\title{
Studi Keterkaitan Kapabilitas Inovasi dan Kinerja Inovasi UKM Alas Kaki di Mojokerto
}

\author{
Benny Lianto ${ }^{1}$, Esti Dwi Rinawiyanti ${ }^{2}$, Fendy Soeharsono ${ }^{3}$ \\ ${ }^{1,2,3)}$ Fakultas Teknik, Jurusan Teknik Industri, Universitas Surabaya \\ Raya Kalirungkut, Surabaya 60293, Indonesia
}

Email:b_lianto@ubaya.ac.id, estidwi@staff.ubaya.ac.id,fendysoeharsono@gmail.com

\begin{abstract}
This paper presents the results of a study on the relationship of innovation capabilities and performance of SMEs related to innovation activity (innovation performance) by taking into account the characteristics of the company in footwear Small and Medium Enterprises (SMEs) in Mojokerto. Innovation capabilities of SMEs was measured using the concept of Technological Innovation Capabiliities (TIC) with 7 (seven) dimensions of capability, ie learning capability, R\&D capability, manufacturing capability, marketing capability, resources allocatioin capability, organizational capability, and strategic planning capabilities; while the innovation performance of SMEs related activity was measured using the concept of Technological innovation performnace (TIP) with 4 (four) dimensions of performance, namely sales performance, innovation performance, product performance, and sales growth performance. Characteristics of SMEs were described through 4 main variables, namely the scale of the business, the company age, the type of product, and the location of the business location. This study was conducted on 82 Footwear SMEs in Mojokerto, which is in Sooko (village of Wringin Rejo, Japan, Karang Kedawang, Jampirogo and Sambiroto), Trowulan District (Pakis village), Pungging District (Tunggal Pager village) and Puri District. The process of data collection was done by interviews and questionnaires to the owners and managers of SMEs. The sampling method used was non-probability purposive sampling and the population used was footwear SMEs in Mojokerto. The data analysis technique used was structural equation modeling (SEM) based on the Component or Variance - PLS program operated through SmartPLS version 2.0.The results of study showed that, manufacturing capability was predicted to affect product performance and organizational capability was estimated to give an impact on the innovation capability, sales growth and sales performance. Some dimensions of innovation capabilities that have absolutely no influence on the performance of SMEs were learning capability, R\&D capability, resources allocation capability, marketing capability, and strategic capability. Results of Manova analysis stated that the characteristics of SMEs (the location of SMEs) gave effect to both the innovation capabilities and the innovation performance of SMEs.
\end{abstract}

Keywords: kapabilitas inovasi, kinerja inovasi, UKM alas kaki, Mojokerto 


\section{PENDAHULUAN}

Usaha Kecil dan Menengah (UKM) mempunyai peran penting dan strategis dalam pembangunan ekonomi nasional. Kontribusi UKM terhadap produk domestik bruto (PDB) nasional mencapai 53\% dengan pertumbuhan pasar diperkirakan meningkat, dari Rp 11,6 triliun pada 2010 menjadi Rp 18,6 triliun pada 2014 [5]. Mengingat peran tersebut, pengembangan UKM perlu mendapatkan perhatian yang besar, baik dari pemerintah maupun masyarakat agar dapat berkembang lebih kompetitif.

Salah satu sektor industri yang dikembangkan dan mendapat skala prioritas dari Dinas Perindustrian dan Perdagangan Jawa Timur, adalah industri alas kaki [6]. Jumlah sentra industri kecil menengah alas kaki di Jawa Timur menurut Dinas Perdagangan dan Perindustrian (Disperindag) sebanyak 1.840 unit usaha. Dengan jumlah sentra industri kecil menengah alas kaki di Jawa Timur yang sedemikian besar dapat dipastikan bahwa tingkat persaingan antara industri alas kaki semakin meningkat. Selain itu, pesaing tidak hanya datang dari sesama industri alas kaki dalam negeri, tetapi juga bisa datang dari industri alas kaki di luar negeri, seperti: China, India, dan Vietnam. Oleh karena itu, upaya peningkatan keunggulan dan daya saing UKM menjadi semakin penting dan mendesak dewasa ini.

Telah banyak penelitian dan cara yang dilakukan untuk meningkatkan keunggulan dan daya saing UKM. Salah satunya adalah melalui aktivitas inovasi [8]. Inovasi sebagai aspek penting dan vital serta merupakan salah satu jaminan bagi perusahaan atau organisasi dalam meningkatkan daya saingnya telah diakui oleh beberapa studi dan penelitian. Abereijo et al [4] mengatakan bahwa inovasi memiliki asosiasi yang kuat dengan keberhasilan perusahaan dalam menopang kinerja dan pertumbuhan usahanya. Beberapa studi empiris pada beberapa industri kecil dan menengah di berbagai negara juga menunjukkan ada hubungan yang kuat antara innovative behavior dengan pencapaian kinerja perusahaan [10]. Shang and Jolly [13] mengatakan, di tengah isu globalisasi dan perubahan teknologi yang semakin cepat dewasa ini, terdapat banyak peluang dan tantangan bagi perusahaan di negara-negara berkembang untuk meningkatkan aktivitas inovasinya melalui peningkatan Technological Innovation Capability (TIC) yang selanjutnya dapat menjadi pemicu utama dalam peningkatan daya saing dan pengembangan ekonomi dalam jangka panjang.

Kapabilitas inovasi atau Technological Innovation Capabilty (TIC) adalah kumpulan karakteristik komprehensif dari suatu perusahaan atau organisasi yang dapat digunakan untuk memfasilitasi dan mendukung strategi inovasi teknologinya [4].

Beberapa studi yang terkait dengan proses pengembangan kapabilitas inovasi (TIC) pada berbagai industri di berbagai negara, khususnya negara berkembang, (Kim, 1997 [12]; Bell, 2006 [3]; Arvanitis, 2006 [2]; Dodgson, 2009 [7] menyatakan bahwa kapabilitas inovasi memiliki peranan vital dalam meningkatkan kinerja perusahaan dan daya saing perusahaan. Yam et al [16] menyebutkan kinerja perusahaan tersebut dengan istilah Technological Innovation Performance (TIP). Terdapat 4 (empat) indikator kinerja yang digunakan dalam mengukur TIP, yakni: kinerja penjualan (sales performance), kinerja inovasi (innovation performance), kinerja produk (product performance), dan pertumbuhan penjualan (sales growth). Kinerja penjualan, kinerja inovasi, dan pertumbuhan penjualan umumnya diukur dengan variable tunggal (single item variable), sedangkan kinerja produk diukur dengan beberapa variabel (multi item variable).

Penelitian awal tentang keterkaitan kapabilitas inovasi terhadap kinerja inovasi dilakukan oleh Yam et al [15]. Penelitian ini bermaksud untuk mempelajari keterkaitan dan pengaruh Technological Innovation Capabilities (TICs) terhadap Technological Innovation Performance (TIP). Hasil penelitiannya pada 200 sampel perusahaan 
manufaktur (industri besar) di Hongkong ini menunjukkan bahwa learning capability sama sekali tidak memiliki hubungan dengan semua parameter TIP. Sedangkan R\&D capability hanya memiliki hubungan dengan product performace. Resorces allocation capability dan manufacturing capability justru hanya memiliki hubungan dengan sales performance, marketing capability memiliki hubungan yang kuat dengan sales growth, sedangkan organization capability memiliki hubungan terhadap sales performance dan innovation performance. Strategic planning capability hanya memiliki keterkaitan dengan product performance.

Selanjutnya, dari penelitian yang dikemukakan Karagouni dan Papadopoulos [11] diperoleh gambaran dampak TIC perusahaan terhadap daya saing industri. Penelitian ini dilakukan pada industri furniture (industri besar) dengan klasifikasi kapabilitas inovasi dengan tujuh (7) dimensi TIC: (1) learning, (2) R\&D, (3) manufacturing, (4) marketing, (5) organizational, (6) resources allocation, (7) strategic. Hasil penelitian menunjukkan bahwa empat (4) dimensi yakni: marketing, resources allocation, learning, dan strategic memberi pengaruh signifikan terhadap daya saing perusahaan, khususnya pertumbuhan penjualan dan daya saing produk.

Penelitian tentang TIC pada UKM di Indonesia dilakukan oleh Siyamtina [14] dengan mengidentifikasi pengaruh faktor internal dan faktor eksternal terhadap kemampuan inovasi yang meliputi 7 dimensi TIC. Hasil penelitian pada 100 UKM di Semarang tersebut menyimpulkan bahwa semakin baik usaha pengelolaan faktor internal yang dimiliki UKM (keberadaan divisi riset dan pengembangan, kesesuaian antara kemampuan dan keahlian karyawan dengan tugas mereka, program pelatihan dan pengembangan sumberdaya manusia, serta penggunaan mesin dengan teknologi baru) dan faktor eksternal (dukungan finansial dan dukungan riset- pengembangan dari pihak luar, penggunaan intellectual property rights, serta interaksi dengan pihak luar), maka kemampuan inovasi akan semakin meningkat.

Secara keseluruhan seluruh penelitian sebelumnya hanya mengkaji keterkaitan kapabilitas inovasi (TIC) dan kinerja inovasi (TIP) pada berbagai skala usaha, namun belum mencoba mengaitkan dan memperhatikan bagaimana pengaruh beberapa karakteristik perusahaan secara lebih luas. Studi dan penelitian ini secara khusus dilakukan dengan tujuan untuk mengkaji bagaimana keterkaitan kapabilitas inovasi dan kinerja inovasi UKM alas kaki di Mojokerto (Jawa Timur) dengan memperhatikan beberapa karateristik UKM. Diharapkan hasil penelitian ini bisa memberikan masukan dan kontribusi penting bagi pengembangan UKM pada umumnya dan UKM alas kaki di Mojokerto khususnya, dalam meningkatkan keunggulan dan daya saingnya berbasis pada karakteristik yang dimiliki.

\section{Metode Penelitian}

Industri yang dijadikan obyek dalam penelitian ini adalah industri alas kaki berskala kecil dan menengah di Mojokerto Jawa Timur. Alasan pemilihan obyek penelitian tersebut adalah karena industri alas kaki merupakan sektor usaha yang menjadi prioritas pengembangan bagi Disperindag Jawa Timur. Data yang digunakan pada penelitian ini meliputi data primer dan data sekunder. Data primer diperoleh melalui wawancara, observasi, dan pembagian kuisioner kepada 82 UKM alas kaki di Mojekerto yaitu di Kecamatan Sooko (Desa Wringin Rejo, Japan, Karang Kedawang, Jampirogo dan Sambiroto), Kecamatan Trowulan (Desa Pakis), Kecamatan Pungging (Desa Tunggal Pager) dan Kecamatan Puri. Sedangkan data sekunder didapatkan melalui data-data yang tersedia di instansi terkait dan internet. Metode sampling yang digunakan pada penelitian ini adalah nonprobability, yaitu purposivesampling dengan populasi yang digunakan adalah UKM alas kaki di Mojokerto. Teknik analisis yang digunakan dalam penelitian ini adalah SPSS dan structural 
equation modeling (SEM) berbasis pada Component atau Variance-PLS yang dioperasilan melalui program SmartPLS versi 2.0

\section{Hasil dan Pembahasan}

Berdasarkan hasil pengolahan data menggunakan bantuan software SPSS dan SmartPLS versi 2.0 diperoleh beberapa hasil dan temuan sebagai berikut:

\section{Analisis Deskriptif}

Hasil analisa deskriptif dari UKM alas kaki di Mojokerto ditunjukkan di Tabel 3. Mayoritas UKM alas kaki di Mojokerto berusia antara 610 tahun $(36,25 \%)$, merupakan usaha kecil (44\%), berlokasi di kota Mojokerto (62,5\%), jumlah pekerja antara 21-25 orang, usia pekerja 26-30 tahun (8,75\%), pendidikan pekerja lulusan SMA (50\%), menghasilkan 101-150 kodi per bulan (33,75\%), memproduksi sepatu (66,25\%), dan area pemasaran didominasi di daerah Jawa Timur $(52,5 \%)$.

Tabel 3. Analisa Deskriptif UKM Alas Kaki di Mojokerto

\begin{tabular}{|l|l|}
\hline \multicolumn{1}{|c|}{ Variabel } & \multicolumn{1}{|c|}{ Hasil Analisis } \\
\hline Usia perusahaan & $\begin{array}{l}36,25 \% \text { antara 6-10 tahun, 32,5\% antara 11-15 tahun, 16,25\% antara 0-5 } \\
\text { tahun dan sisanya 15\% berusia lebih dari 16 tahun. }\end{array}$ \\
\hline Skala UKM & $\begin{array}{l}\text { skala kecil (44\%), skala usaha mikro (35\%), dan sisanya 21\% merupakan } \\
\text { usaha skala menengah }\end{array}$ \\
\hline $\begin{array}{l}\text { Jumlah tenaga } \\
\text { kerja }\end{array}$ & $\begin{array}{l}21,25 \% \text { kurang dari 5 orang, 15\% antara 5-10 orang pekerja, 8,75\% antara } \\
11-15 \text { orang pekerja, 12,5\% antara 16-20 orang pekerja, 23,75\% antara 21- } \\
\text { 25 orang pekerja, serta sisanya 18,75\% antara 26-30 orang pekerja. }\end{array}$ \\
\hline Omset/bulan & $\begin{array}{l}33,75 \% \text { menghasilkan 101-150 kodi alas kaki perbulan, kemudian 31,25\% } \\
\text { menghasilkan 51-100 kodi alas kaki perbulan, 27,5\% memproduksi lebih } \\
\text { dari 150 kodi alas kaki perbulannya dan sisanya 7,5\% hanya mampu } \\
\text { menghasilkan kurang dari 50 kodi alas kaki perbulan. }\end{array}$ \\
\hline $\begin{array}{l}\text { Jenis produk yang } \\
\text { paling banyak } \\
\text { diproduksi }\end{array}$ & $\begin{array}{l}\text { 66,25\% memproduksi sepatu (sepatu olah raga, imitasi maupun sepatu } \\
\text { kulit), 21,25\% memproduksi keduanya (baik itu sandal maupun sepatu) dan } \\
\text { sisanya 12,5\% memproduksi sandal (sandal kulit maupun sandal jepit). }\end{array}$ \\
\hline Usia tenaga kerja & $\begin{array}{l}\text { Sebanyak 28,75\% berusia 26-30 tahun, 26,25\% berusia 20-25 tahun, 21,25\% } \\
\text { berusia 36- 40 tahun, 16,25\% berusia 31-35 tahun dan 7,5\% berusia kurang } \\
\text { dari 20 tahun. }\end{array}$ \\
\hline $\begin{array}{l}\text { Pendidikan tenaga } \\
\text { kerja }\end{array}$ & $\begin{array}{l}\text { Sebanyak 8,75\% lulusan SD-SMP, kemudian 41,25\% lulusan SMP-SMA dan } \\
\text { kemudian sisanya 50\% memiliki pekerja lulusan SMA }\end{array}$ \\
\hline
\end{tabular}

\section{Analisis Tingkat Kapabilitas inovasi}

Analisis tingkat kapabilitas inovasi dilakukan dengan menghitung rata-rata keseluruhan (grand mean) dari seluruh variabel pada setiap dimensi. Selanjutnya nilai grand mean dikelompokkan (rendah, sedang, tinggi) seperti ditabel 4 dengan perhitungan interval skala sebagai berikut:

$$
\text { Interval }=\frac{(N-1)}{3}=\frac{(5-1)}{3}=\frac{4}{3}=1,33
$$

Keterangan: N= Skala Likert (1-5)

Tabel 4. Skala Pengukuran Grand Mean Variabel TIC dan TIP di Mojokerto

\begin{tabular}{|c|c|}
\hline Skala & Keterangan \\
\hline $1,00-2,33$ & Rendah \\
\hline $2,34-3,67$ & Sedang \\
\hline $3,68-5$ & Tinggi \\
\hline
\end{tabular}

Hasil perhitungan mean dan grand mean pada tiap variabel dimensi technological innovation capabilities ditampilkan pada tabel 5. Berdasarkan hasil perhitungan diperoleh bahwa nilai grand mean seluruh dimensi kapabilitas inovasi menunjukkan kategori tinggi. Grand mean tertinggi terdapat pada dimensi Strategy Capability $(4,32)$ dengan kontribusi terbesar diperoleh dari variabel yang menunjukkan bahwa UKM alas kaki Mojokerto telah memiliki strategi yang baik dalam menghadapi pesaing $(4,4)$. Nilai grand 
mean dimensi Learning Capability $(4,23)$ juga menunjukkan angka yang relatif tinggi dibanding dimensi lain. Hal ini menunjukkan bahwa pekerja di UKM alas kaki Mojokerto memiliki tingkat pendidikan yang cukup baik dan berpengaruh terhadap kinerja UKM, begitu pula untuk faktor usia dari pekerja serta pengalaman kerja. Namun terlihat bahwa kontribusi terbesar kapabilitas belajar diperoleh dari pengalaman kerja para pekerja $(4,51)$.

Tabel 5. Skor Mean dan Grand Mean TICUKM Alas Kaki di Mojokerto

\begin{tabular}{|c|c|c|c|c|}
\hline Dimensi & Variabel & Mean & $\begin{array}{c}\text { Grand } \\
\text { mean }\end{array}$ & $\begin{array}{l}\text { Kode Var } \\
\text { Konstruk }\end{array}$ \\
\hline \multirow{3}{*}{$\begin{array}{l}\text { Learning } \\
\text { Capability }\end{array}$} & $\begin{array}{l}\text { Tingkat pendidikan pekerja mempengaruhi } \\
\text { produktivitas }\end{array}$ & 3,96 & \multirow{3}{*}{$\begin{array}{c}4,23 \\
\text { (Tinggi) }\end{array}$} & L1 \\
\hline & Usia pekerja mempengaruhi produktivitas & 4,23 & & L2 \\
\hline & Pengalaman kerja mempengaruhi kinerja UKM & 4,51 & & L3 \\
\hline \multirow{6}{*}{$\begin{array}{l}\text { Resources } \\
\text { allocation } \\
\text { capability }\end{array}$} & Jumlah pekerja mempengaruhi produktivitas & 4,32 & \multirow{6}{*}{$\begin{array}{c}4,12 \\
\text { (Tinggi) }\end{array}$} & $\mathrm{R} 4$ \\
\hline & Modal mempengaruhi kinerja UKM & 4,13 & & R5 \\
\hline & Bahan baku mempengaruhi kinerja UKM & 4,35 & & R6 \\
\hline & $\begin{array}{l}\text { UKM menggunakan outsourcing untuk beberapa } \\
\text { bagian proses produksi }\end{array}$ & 4,01 & & $\mathrm{R} 7$ \\
\hline & Lokasi UKM dekat dengan pasar bahan baku & 4,06 & & $\mathrm{R} 8$ \\
\hline & Lokasi UKM saat ini dekat dengan pelanggan & 3,82 & & R9 \\
\hline \multirow{10}{*}{$\begin{array}{l}R \& D \\
\text { Capability }\end{array}$} & Inovasi penting untuk peningkatan kerja UKM & 4,41 & \multirow{10}{*}{$\begin{array}{c}4,21 \\
\text { (Tinggi) }\end{array}$} & $\mathrm{RnD} 10$ \\
\hline & UKM perlu melakukan inovasi produk & 4,16 & & RnD11 \\
\hline & UKM perlu melakukan inovasi poses & 4,2 & & RnD12 \\
\hline & UKM perlu melakukan inovasi pemasaran & 4,26 & & RnD13 \\
\hline & UKM aktif mengeluarkan produk baru & 4,02 & & RnD14 \\
\hline & Produk yang di keluarkan benar-benar baru & 4,03 & & RnD15 \\
\hline & $\begin{array}{lll}\begin{array}{l}\text { Produk yang dikeluarkan } \\
\text { modifikasi produk sebelumnya }\end{array} & \text { merupakan } & \text { hasil } \\
\end{array}$ & 4,05 & & RnD16 \\
\hline & $\begin{array}{l}\text { UKM sering melakukan perubahan pada warna } \\
\text { produk }\end{array}$ & 4,35 & & RnD17 \\
\hline & $\begin{array}{l}\text { UKM sering melakukan perubahan pada bentuk } \\
\text { produk }\end{array}$ & 4,4 & & RnD18 \\
\hline & $\begin{array}{l}\text { UKM sering melakukan perubahan pada } \\
\text { motif/sablon }\end{array}$ & 4,2 & & RnD19 \\
\hline \multirow{5}{*}{$\begin{array}{l}\text { Manufactu } \\
\text {-ring } \\
\text { Capability }\end{array}$} & UKM pernah melakukan pembelian alat & 4,07 & \multirow{5}{*}{$\begin{array}{c}4,19 \\
\text { (Tinggi) }\end{array}$} & Man20 \\
\hline & Alat yang dibeli dapat meningkatkan produktivitas & 4,18 & & Man21 \\
\hline & $\begin{array}{l}\text { Alat yang dibeli dapat meningkatkan kualitas } \\
\text { produk }\end{array}$ & 4,03 & & $\operatorname{Man} 22$ \\
\hline & $\begin{array}{l}\text { UKM memiliki standar tertentu didalam proses } \\
\text { produksi }\end{array}$ & 4,27 & & Man23 \\
\hline & $\begin{array}{l}\text { Kemampuan pekerja yang dimiliki sesuai dengan } \\
\text { kapabilitas UKM }\end{array}$ & 4,4 & & Man24 \\
\hline \multirow{6}{*}{$\begin{array}{l}\text { Organizati } \\
\text { onal } \\
\text { Capability }\end{array}$} & $\begin{array}{l}\text { Organisasi UKM mampu mengelola bantuan modal } \\
\text { dari pemerintah }\end{array}$ & 3,62 & \multirow{6}{*}{$\begin{array}{c}3,68 \\
\text { (Tinggi) }\end{array}$} & $\mathrm{O} 25$ \\
\hline & $\begin{array}{l}\text { Organisasi UKM mampu bekerja sama dengan } \\
\text { pemerintah dalam pelaksanaan tranning }\end{array}$ & 3,62 & & $\mathrm{O} 26$ \\
\hline & $\begin{array}{l}\text { Organisasi UKM mempu mengusahakan bantuan } \\
\text { mesin dan alat dari pemerintah }\end{array}$ & 3,18 & & $\mathrm{O} 27$ \\
\hline & $\begin{array}{l}\text { Organisasi UKM mampu mengusahakan bantuan } \\
\text { pelatihan dari pemerintah }\end{array}$ & 3,67 & & $\mathrm{O} 28$ \\
\hline & $\begin{array}{l}\text { Organisasi UKM mampu mengusahakan bantuan } \\
\text { pendampingan dari pemerintah }\end{array}$ & 3,58 & & O29 \\
\hline & $\begin{array}{l}\text { Kerjasama dengan pihak lain perlu dilakukan } \\
\text { untuk menjalankan UKM }\end{array}$ & 4,42 & & O30 \\
\hline \multirow{2}{*}{$\begin{array}{l}\text { Marketing } \\
\text { Capability }\end{array}$} & Produk UKM sudah dapat memenuhi kriteria pasar & 4,16 & \multirow{2}{*}{$\begin{array}{c}3,90 \\
\text { (Tinggi) }\end{array}$} & M31 \\
\hline & Harga produk UKM setara dengan produk pesaing & 4,11 & & M32 \\
\hline
\end{tabular}




\begin{tabular}{|c|c|c|c|c|}
\hline & $\begin{array}{l}\text { UKM menawarkan produk secara langsung dengan } \\
\text { membawa sampel kepada pelanggan }\end{array}$ & 4,38 & & M33 \\
\hline & $\begin{array}{l}\text { UKM memberikan harga khusus pada pembelian } \\
\text { dengan jumlah besar }\end{array}$ & 3,92 & & M34 \\
\hline & UKM membuat brosur untuk melakukan promosi & 2,03 & & M35 \\
\hline & UKM pernah ikut serta dalam pameran & 3,57 & & M36 \\
\hline & $\begin{array}{l}\text { UKM selalu melakukan pengiriman barang tepat } \\
\text { waktu }\end{array}$ & 4,11 & & M37 \\
\hline & UKM memiliki merek sendiri untuk produknya & 4,21 & & M38 \\
\hline & $\begin{array}{l}\text { UKM ingin mendaftarkan atau mematenkan merek } \\
\text { produknya }\end{array}$ & 4,26 & & M39 \\
\hline & $\begin{array}{l}\text { UKM melakukan pengiriman produk melalui } \\
\text { ekspedisi }\end{array}$ & 4,26 & & M40 \\
\hline \multirow{5}{*}{$\begin{array}{l}\text { Strategy } \\
\text { Capability }\end{array}$} & $\begin{array}{l}\text { UKM memiliki strategi khusus untuk menghadapi } \\
\text { pesaing }\end{array}$ & 4,4 & \multirow{5}{*}{$\begin{array}{c}4,32 \\
\text { (Tinggi) }\end{array}$} & S41 \\
\hline & $\begin{array}{lccc}\text { UKM } & \text { memiliki strategi } & \text { khusus } & \text { untuk } \\
\text { mempertahankan pelanggan } & & \\
\end{array}$ & 4,32 & & $\mathrm{~S} 42$ \\
\hline & $\begin{array}{llll}\text { UKM mengevaluasi } & \text { kinerja } & \text { pekerja } & \text { yang } \\
\text { dimilkinya } & & & \\
\end{array}$ & 4,3 & & $\mathrm{~S} 43$ \\
\hline & $\begin{array}{l}\text { Kualitas produk yang dihasilkan UKM sesuai } \\
\text { dengan permintaan pasar }\end{array}$ & 4,26 & & $\mathrm{~S} 44$ \\
\hline & Produk UKM dapat bersaing dengan produk impor & 4,33 & & $\mathrm{~S} 45$ \\
\hline
\end{tabular}

\section{Analisa Tingkat Kinerja Inovasi UKM}

Dengan cara yang sama pada analisis tingkat kapabilitas inovasi, gambaran tingkat kinerja empat dimensi technological inovation performance (TIP) dan 11 variabel dapat dilihat pada tabel 6 . Nilai rata-rata tertinggi TIP diperoleh oleh dimensi Product Performance $(3,8)$, terutama dari aspek kualitas produk. Berdasarkan pengamatan, kualitas produk alas kaki UKM Mojokerto, memang banyak mendapat pengakuan dari berbagai pihak, terutama dari perusahaan menengah dan besar serta pemegang merk yang sering memberikan order produksi kepada UKM di Mojokerto. Dipihak lain, dimensi Sales Performance $(2,81)$ dan Innovation Performance $(2,68)$ tergolong kategori sedang, sedangkan Nilai grand mean terendah dan tergolong kategori rendah terdapat pada dimensi Sales Growth (2.16). Kondisi ini besar kemungkinan disebabkan karena UKM alas kaki di Mojokerto sebagian besar hanya fokus menerima order dan pekerjaan produksi dari pemegang merk sehingga UKM kurang aktif melakukan kegiatan pemasaran dan mencari pelanggan baru. Demikian pula dalam menghasikan produk-produk baru (inovasi), UKM alas kaki di Mojokerto lebih banyak hanya mengandalkan desain dan model-model yang telah ditentukan oleh pemberi order produksi.

\section{Multivariate Analysis of Variance (MANOVA) pada Kapabilitas Inovasi dan Kinerja Inovasi UKM}

Analisis MANOVA dilakukan untuk mengetahui apakah ada perbedaan kapabilitas inovasi (TIC) dan kinerja inovasi UKM (TIP) jika dilihat dari karakteristik UKM. Pengolahan data menggunakan tingkat $\alpha=$ $5 \%$ untuk masing- masing Multivariatetest. Hasil rekapitulasi hasil seperti di tabel 7 .

Tabel 6. Skor Mean dan GrandMean TIP UKM Alas Kaki di Mojokerto

\begin{tabular}{|l|l|c|c|l|}
\hline \multicolumn{1}{|c|}{ Dimensi } & \multicolumn{1}{|c|}{ Variabel } & Mean & $\begin{array}{c}\text { Grand } \\
\text { mean }\end{array}$ & $\begin{array}{l}\text { Kode Var. } \\
\text { Konstruk }\end{array}$ \\
\hline $\begin{array}{l}\text { Product } \\
\begin{array}{l}\text { Performance } \\
\text { (selama 3 tahun } \\
\text { terakhir }\end{array}\end{array}$ & Kualitas produk & 4 & \multirow{2}{*}{$\begin{array}{c}3,8 \\
\text { (Tinggi) }\end{array}$} & TIP71 \\
\cline { 2 - 3 } & Keunggulan harga & 3,72 & TIP72 \\
\cline { 2 - 3 } & Daya saing di pasar & 3,87 & & TIP73 \\
\hline
\end{tabular}




\begin{tabular}{|c|c|c|c|c|}
\hline \multirow{2}{*}{$\begin{array}{l}\text { dibandingkan } \\
\text { dengan pesaing) }\end{array}$} & Keunikan produk & 3,62 & & TIP74 \\
\hline & Rata-rata peluncuran produk baru & 3,77 & & TIP75 \\
\hline $\begin{array}{l}\text { Sales } \\
\text { Performance }\end{array}$ & $\begin{array}{l}\text { Jumlah penjualan produk mengalami } \\
\text { peningkatan selama } 3 \text { bulan terakhir }\end{array}$ & 2,81 & $\begin{array}{c}2,81 \\
\text { (Sedang) }\end{array}$ & TIP1 \\
\hline $\begin{array}{l}\text { Innovation } \\
\text { Performance }\end{array}$ & $\begin{array}{l}\text { Prosentase mengeluarkan produk baru } \\
\text { selama } 3 \text { bulan terakhir }\end{array}$ & 2,68 & $\begin{array}{c}2,68 \\
\text { (Sedang) }\end{array}$ & TIP2 \\
\hline \multirow{4}{*}{ Sales Growth } & $\begin{array}{l}\text { Prosentase peningkatan penjualan secara } \\
\text { keseluruhan selama } 3 \text { bulan terakhir }\end{array}$ & 2,18 & \multirow{4}{*}{$\begin{array}{c}2,16 \\
\text { (Rendah) }\end{array}$} & TIP3 \\
\hline & $\begin{array}{l}\text { Peningkatan omzet dibandingkan tahun lalu } \\
\text { (dalam \%) }\end{array}$ & 2,06 & & TIP4 \\
\hline & $\begin{array}{l}\text { Peningkatan jumlah pelanggan selama } \\
\text { setahun terakhir }\end{array}$ & 2,31 & & TIP5 \\
\hline & $\begin{array}{l}\text { Perluasan area pemasaran selama setahun } \\
\text { terakhir }\end{array}$ & 2,07 & & TIP6 \\
\hline
\end{tabular}

Dari hasil uji manova yang telah dilakukan dapat diketahui bahwa usia operasi UKM, skala usaha UKM, dan jenis produksi tidak berpengaruh terhadap TIC dan TIP. Tetapi letak lokasi UKM berpengaruh terhadap TIC dan TIP. Berdasarkan hasil obersevasi dan analisis terhadap data tingkat kapabilitas inovasi dan tingkat kinerja inovasi terlihat bahwa UKM alas kaki yang memiliki letak lokasi usaha di tengah kota (dikelola dalam suatu kampung industri) relatif memiliki tingkat kapabilitas dan kinerja inovasi lebih baik dibanding UKM alas kaki yang memiliki lokasi usaha di pinggiran kota (dikelola mandiri).

Tabel 7. Rekapitulasi Hasil MANOVA

\begin{tabular}{|l|l|l|}
\hline \multicolumn{1}{|c|}{ Variabel } & \multicolumn{1}{c|}{ TIC } & \multicolumn{1}{c|}{ TIP } \\
\hline Umur UKM & Tidak ada perbedaan & Tidak ada perbedaan \\
\hline Skala UKM & Tidak ada perbedaan & Tidak ada perbedaan \\
\hline Jenis Produksi UKM & Tidak ada perbedaan & Tidak ada perbedaan \\
\hline Letak UKM & Ada perbedaan & Ada perbedaan \\
\hline
\end{tabular}

\section{Analisis Structural Equation Modeling (SEM)}

Analisis SEM yang digunakan pada penelitian ini berbasis variance atau component dengan menggunakan software smartPLS 2.0. Indikator konstruk TIC dan TIP dicantumkan di tabel 5 dan tabel 6 . Sedangkan model awal struktural hubungan keterkaitan dimensi TIC dan TIP dijelaskan pada gambar 1. Model awal penelitian ini diadopsi dari model TIC audit framework yang dikemukakan oleh Yam et al [16] yang dimodifikasi dengan memasukkan karakteristik IKM sebagai variabel kontrol. Kerangka awal penelitian ini menggambarkan hal-hal sebagai berikut: (1) Parameter atau faktor yang dipertimbangkan pada Technological Innovation Capabilities (TICs) adalah: learning capability, $\mathrm{R} \& \mathrm{D}$ capability, resources allocation capability, manufacturing capability, marketing capability, organization capability, dan strategic planning capability; (2) Parameter atau faktor yang dipertimbangkan pada Technological Innovation Performance (TIP) adalah: sales performance, innovation performance, product performance, dan sales growth; Karakteristik IKM, seperti: usia operasi UKM, skala usaha UKM, jenis produk dan letak lokasi UKM akan menjadi control variable 


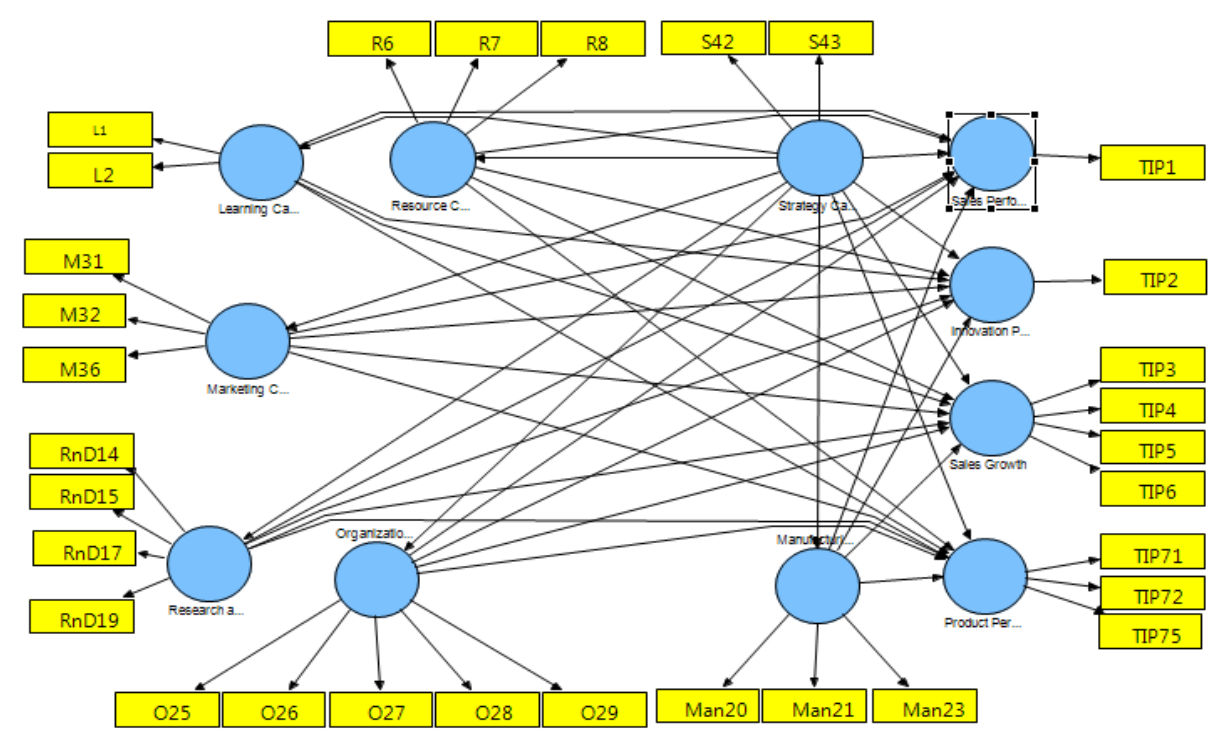

Gambar 1. Model Awal Struktural Hubungan TIC dan TIP

Proses selanjutnya dilakukan pengujian model dengan melakukan tahapan sebagai berikut: pada tahap awal dilakukan proses calculate dengan menggunakan bootstrapping, selanjutnya dilakukan evaluasi terhadap hasil calculate model tersebut. Hasil evaluasi terhadap outer model menunjukkan bahwa semua konstruk dikatakan sudah reliable karena memiliki composite reliability dan cronbanch's alphanya diatas 0.6 , Selain itu dapat dikatakan semua indikator telah valid karena telah memiliki factor loading diatas 0.50 maka dianggap telah memenuhi syarat dari convergent validity. Sedangkan discriminant validity dapat dilihat dari nilai cross loading. Nilai korelasi indikator terhadap konstruknya telah menunjukkan lebih besar dibandingkan nilai korelasi antara indikator dengan konstruk lain. Sehinnga secara keseluruhan dapat dikatakan seluruh konstruk telah reliabel dan valid.

Hasil model hubungan antar TIC dan TIP yang telah disusun berdasarkan hasil evaluasi diatas, ditampilkan di gambar 2. Sedangkan hasil output dari path coefficients yang berpengaruh berdasarkan nilai t-statistik dan nilai koefisien parameternya disajikan di tabel 8.

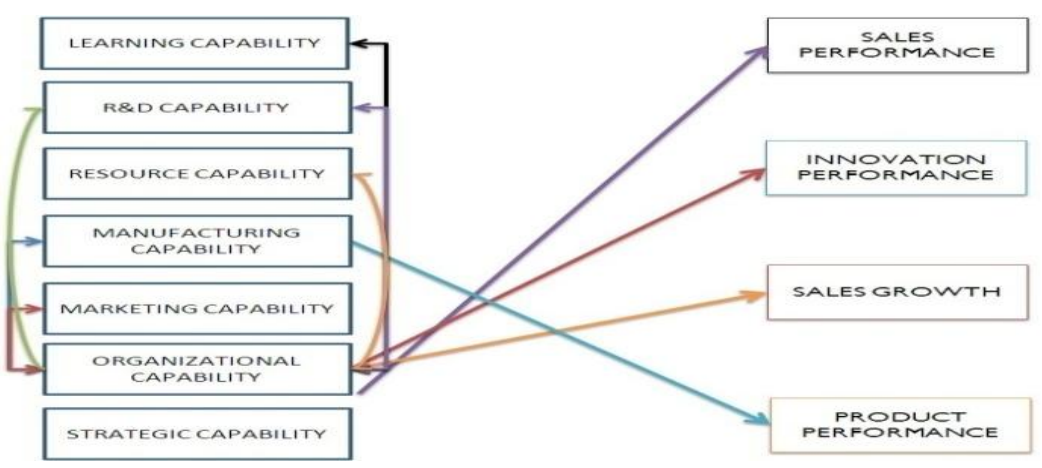

Gambar 2 Model Hubungan Antar Konstruk

Tabel 8. Konfirmatori Hasil Path Coefficient

\begin{tabular}{|l|c|c|}
\hline \multicolumn{1}{|c|}{ Hasil Keterkaitan } & $\begin{array}{c}\text { Original } \\
\text { Sample }(O)\end{array}$ & $\begin{array}{c}\text { T Statistic } \\
(\mid \text { O/STERR } \mid\end{array}$ \\
\hline Manufacturing Capability ->Product Performance & 0,315628 & 2,555363 \\
\hline Organizational Capability ->Innovation Performance & 0,653543 & 3,42489 \\
\hline Organizational Capability -> Learning Capability & 0,301334 & 2,034878 \\
\hline
\end{tabular}




\begin{tabular}{|l|c|c|}
\hline Organizational Capability ->Manufacturing Capability & 0,3767 & 3,362322 \\
\hline Organizational Capability ->Marketing Capability & 0,764809 & 21,10758 \\
\hline $\begin{array}{l}\text { Organizational Capability ->Research and Development } \\
\text { Capability }\end{array}$ & 0,434899 & 4,736834 \\
\hline Organizational Capability ->Resources allocation capability & 0,73444 & 15,82205 \\
\hline Organizational Capability ->Sales Growth & 0,676826 & 3,46466 \\
\hline Organizational Capability ->Sales Performance & 0,495939 & 2,589333 \\
\hline
\end{tabular}

Berdasarkan analisis terhadap model, diperoleh beberapa temuan sebagai berikut:

- Manufacturing capability memberikan pengaruh positif terhadap product performance dengan nilai t-statistik lebih besar dari 1,96 yaitu sebesar 2,555363 dan nilai koefisien parameternya 0.315628 . Hal ini dapat dikatakan bahwa kapabilitas manufaktur UKM alas kaki di kota Mojokerto memberikan peran penting terhadap pencapaian kinerja produk yang dihasilkan, terutama dalam menghasilkan produk-produk yang berkualitas dan memiliki daya saing. Terbentuknya kapabilitas manufaktur UKM alas kaki di Mojokerto ditopang oleh kelengkapan peralatan produksi cukup baik dan memadai. Hasil survey secara langsung menunjukan walaupun skala UKM sebagian besar (79\%) termasuk ketegori usaha mikro dan kecil, akan tetapi alat yang dimiliki sebagian besar lebih dari satu dan sesuai dengan kapasitas produksi yang dibutuhkan. Selain itu, adanya standar kualitas proses produksi dan ketrampilan pekerja produksi yang sesuai dengan kebutuhan (walaupun tingkat pendidikannya rendah) juga menjadi pendukung terbentuknya kapabilitas manufaktur yang tinggi (grand mean= 4,19). Di lain pihak, kinerja produk yang dihasilkan UKM alas kaki Mojokerto telah dikenal memiliki kualitas tinggi dan cukup kompetitif, baik produk sandal maupun sepatu kulit. Hal ini dibuktikan dengan banyaknya UKM alas kaki Mojokerto, terutama yang berlokasi di kampung industri sepatu, yang menerima pekerjaan dan order dari industri skala menengah dan besar dari kota Surabaya (pemegang merk).
- Organization capability memberi pengaruh positif terhadap innovation performance dengan nilai t-statistik 3.42489 dan koefisien parameter 0.653543 . Kapabilitas organisasi, khususnya kemampuan UKM dalam membina hubungan yang baik dengan pemerintah dan instansi terkait, seperti disperindag ternyata sangat membantu UKM dalam meningkatkan kinerja inovasinya, walaupun masih pada tataran kategori sedang $(2,68)$. Dukungan pemerintah terutama melalui seminar, pelatihan, workshop, dan pendampingan yang diberikan kepada UKM alas kaki yang ada di Mojokerto ternyata cukup efektif dalam meningkatkan kemampuan UKM menghasilkan ide-ide produk baru. Hasil wawancara menyebutkan bahwa dari seminar-seminar dan pelatihan yang diadakan secara periodik, para pemilik UKM menjadi lebih terbuka wawasannya, terutama pada desain produk yang diproduksi. Namun potensi ini belum dapat digunakan secara optimal karena sebagian besar UKM hanya terpaku pada modelmodel yang telah diberikan oleh pemegang merk yang menyerahkan kontrak produksi. Jika UKM alas kaki Mojokerto bisa lebih proaktif dalam mempromosikan desaindesain baru mereka dan meningkatkan aktivitas pemasaran secara mandiri, akan membantu UKM alas kaki untuk meningkatkan kinerja usaha dan daya saingnya di masa mendatang.

- Organizational Capability juga memberi mempengaruhi terhadap Sales Growth dengan nilai t-statistik 3.46466 dan koefisien parameter 0.676826 dan juga memberi pengaruh terhadap sales performance dengan nilai t-statistik 2.589333 dan koefisien parameter 0.495939 . Hal ini menunjukkan bahwa 
kapabilitas organisasi, khususnya kemampuan organisasi UKM dalam membina hubungan yang baik dengan berbagai pihak, terutama pemerintah daerah ternyata sangat membantu UKM dalam meningkatkan pertumbuhan dan kinerja penjualannya, walaupun masih memiliki tingkat kinerja kategori sedang. Pertumbuhan dan kinerja penjualan pada UKM alas kaki di Mojokerto yang diperoleh melalui pertumbuhan jumlah pelanggan dan perkembangan area pemasaran dicapai berkat peran serta pemerintah setempat dalam mendukung pemasaran dan memperkenalkan produk alas kaki produksi UKM, terutama dengan mendirikan Kampung Sepatu di daerah Miji, Mojokerto. Strategi pendirian kampung industri yang dikelola secara profesional dan dijadikan salah satu destinasi wisata kota Mojokerto tenyata sangat efektif dalam meningkatkan penjualan produkproduk alas kaki UKM dalam area kampung industri tersebut. Selain itu, adanya kampung industri ini juga mempermudah para industri menengah dan besar (pemegang merk) dalam mengalokasikan order dalam jumlah yang besar karena kumpulan UKM tersebut menghasilkan akumulasi kapasitas produksi yang cukup besar. Pola pengembangan dan pembinaan UKM dengan model kampung industri alas kaki di kota Mojokerto yang disertai dengan usaha peningkatan kemampuan UKM untuk melakukan kegiatan pemasaran secara mandiri dan lebih proaktif, akan berpotensi meningkatkan daya saing UKM alas kaki Mojokerto dimasa mendatang.

- Variabel yang tidak berpengaruh secara signifikan dengan semua variabel TIP adalah learning capability, marketing capability, R\&D capability, resources allocation capability, dan strategic planning capability. Learning capability memiliki keterkaitan dengan Organizational Capability dengan nilai t-statistik 2.034878 dan koefisien parameter 0.3013334 . demikian pula dengan marketing capability,
R\&D capability, dan resources allocation capability walupun tidak memberi pengaruh terhadap TIP namun memiliki keterkaitan dengan Organizational Capability dengan nilai t-statistik 21.10758 dan koefisien parameter 0.764809 (untuk marketing capability), dengan nilai t-statistik 4.736834 dan koefisien parameter 0.434899 (untuk R\&D capability ) dan dengan nilai t-statistik 15.82205 dan koefisien parameter 0.73444 (untuk resources allocation capability). Khusus strategic capability, walaupun memiliki tingkat kapabilitas tertinggi $(4,32)$, peran aspek strategis terhadap kapabilitas inovasi lainnya dan kinerja inovasi UKM belum begitu besar, sehingga dalam model terlihat bahwa keterkaitan strategic capability terhadap dimensi kapabilitas lainnya dan TIP tidak cukup signifikan. Sebagian besar (79\%) skala usaha UKM alas kaki di Mojokerto adalah skala mikro dan kecil, kemunmgkinan menjadi penyebab mengapa permasalahan yang bersifat operasional menjadi lebih dominan dibanding permasalahan yang bersifat strategis.

\section{Simpulan}

Berdasarkan hasil studi ini dapat disimpulkan beberapa hal, sebagai berikut:

- Usia operasi UKM, skala usaha UKM, dan jenis produksi tidak berpengaruh terhadap kapabilitas inovasi dan kinerja inovasi UKM alas kaki di Mojokerto. Tetapi letak lokasi UKM berpengaruh terhadap kapabilitas inovasi sekalgus kinerja inovasi UKM. Berdasarkan hasil obersevasi dan analisis terhadap data tingkat kapabilitas inovasi dan tingkat kinerja inovasi terlihat bahwa UKM alas kaki yang memiliki letak lokasi usaha di tengah kota (dikelolah dalam suatu kampung industri) relatif memiliki tingkat kapabilitas dan kinerja inovasi lebih baik dibanding UKM alas kaki yang memiliki lokasi usaha di pinggiran kota ( yang dikelola mandiri).

- Menurut hasil output pada smartPLS terdapat hubungan antar konstruk TIC 
dengan TIP yang berpengaruh secara signifikan yaitu:

- Manufacturing Capability berpengaruh terhadap Product Performance dengan nilai t-statistik 2,555363 dan koefisien parameter 0,315628.

- Organizational Capability berpengaruh terhadap Innovation Performance dengan nilai t-statistik 3,42489 dan koefisien parameter 0,653543 .

- Organizational Capability berpengaruh terhadap Sales Growth dengan nilai tstatistik 3,46466 dan koefisien parameter 0,676826.

- Organizational Capability berpengaruh terhadap Sales Performance dengan nilai t-statistik 2,589333 dan koefisien parameter 0,495939.

Hubungan antar variabel TIC yang diprediksi memiliki hubungan yang signifikan adalah sebagai berikut:

- Organizational Capability berpengaruh secara signifikan terhadap Learning Capability dengan nilai t-statistik 2,034878 dan koefisien parameter 0,301334 .

- Organizational Capability berpengaruh secara signifikan terhadap Manufacturing Capability dengan nilai t-statistik 3,362322 dan koefisien parameter 0,3767.

- Organizational Capability berpengaruh secara signifikan terhadap Marketing Capability dengan nilai t-statistik 21,10758 dan koefisien parameter 0,764809 .

- Organizational Capability berpengaruh secara signifikan terhadap Research and Development Capability dengan nilai t-statistik 4,736834 dan koefisien parameter 0,434899.

- Organizational Capability berpengaruh secara signifikan terhadap Resources allocation capabilitydengan nilai tstatistik 15,82205 dan koefisien parameter 0,73444 .

\section{Ucapan Terima Kasih}

Tim peneliti menyampaikan terimakasih kepada Lembaga Penelitian dan Pengabdian Masyarakat Universitas Surabaya yang telah mendanai pelaksanaan penelitian ini dengan Surat Perjanjian Pelaksanaan Penugasan Nomor:084/Lit/LPPM-01/FT-TI/VIII/2013 tanggal 1 Agustus

\section{DAFTAR PUSTAKA}

I. Abereijo, Oluwagbemiga, Kehinde, Akinade. (2007). Assessment of the Capabilities for Innovation by Small And Medium Industry in Nigeria, African Journal of Business Management Vol.I (8), November 2007, 209-217.

2. Arvanitis, R., Zhao, W., Qiu, H., \& Xu, J.-n. (2006). Technological learning in six firm in Southern China: success and limitsof an industrialisation model. International Journal of Technology Management, 36 (I-3), 108125.

3. Bell, M. (2006). Time and technological learning in industrilising countries: how long does it take? How fast is it moving (if at all)? International Journal of Technology Management, 36 (I-3), 25-39.

4. Burgelman, R., Maidique, M. A. and Wheelwright, S.C. (2004). Strategic Management of Technology and Innovation, McGraw Hill, New York.

5. Departemen Koperasi. (20l4) Telkom Siapkan Solusi TIK untuk UKM. http://www.depkop.go.id/index.php?option= com_content\&view=article\&id=103:telkomsiapkan-so..[diakses tanggal 6 Mei 20I4]

6. Dinas Perindustrian dan Perdagangan Jawa Timur. (20II). Pelaksanaan Kebijakan Pembangunan Industri Jawa Timur, http://rocana.kemenperin.go.id/phocadownl oad/Forkom_fungsional/

pelaksanaan\%20kebijakan\%20industri\%20di\% 20jatim\%20-\%20kadisperindag\%20jatim.pdf [diakses pada tanggal 20 Desember 2012].

7. Dodgson, M. (2009). Asia's national innovation systems: Institutional adaptability and rigidity in the face of global innovation challenges. 
Asia Pacific Journal of Management, 26 (3), 589-602.

8. Guan, J.(2002), Comparison Study of Industrial Innovation between China and Some European Countries, Production and Inventory Management Journal, Vol. 43, No.3.

9. Guan, J. and Ma, N. (2003), Innovative Capability and Export Performance of Chinese Firms, Technovation, Vol. 23, 737 747.

10. Gunasekaran A, Forker L, Kobu B (2000), Improving operation performance in a small company: a case study,International Journal of Opeations 7Production management.20(3): I-I4.

II.Karagouni-Papadopoulos, (2007). 17-34 MIBES* Transactions on Line, Vol I, Issue I, Autumn 2007.

12.Kim, L. (1997). Imitation to Innovation: the Dynamics of Korea's Technological Learning. Boston: Harvard Business School Press.

13.Shang Juan \& Jolly R D. (20I0), "Accumulation of Technological Innovation Capabilities and Competitive Performance in Chinese Firm: a Quantitative Study", IAMOT 2010,Cairo, Egypt, I-2I.

14.Siyamtinah, Heru Sulistyo, Eny Rahmani. (20II). Model Peningkatan Kinerja melalui Kemampuan inovasi pada UKM di Semarang, Fakultas Ekonomi, Universitas Sultan Agung Semarang, Seminar Nasional IImu Ekonomi Terapan Fakultas Ekonomi UNIMUS 20II.

15. Yam, C. M, Guan, J. C, Pun, K. F. and Tam, P. Y. (2004). "An Audit of Technological Innovation Capabilities in Chinese Firms: Some Empirical Findings in Beijing, China, Research Policy", Vol. 33, No. 8, II 23-I 250.

16. Yam, C. M, Wiiliam Lo, Esther P. Y, Tang \& Anonio, K. W. Lau. (2010). "Technological Innovation Capabilities and Firm Performance, World Academy of Science, Engineering and Technology", 1023-1030. 